\title{
Use of Thoracoscopic Splanchnicectomy for the Relief of Chronic Pancreatic Pain: a Case Series
}

\author{
Galketiya KBa ${ }^{\mathrm{a}}$, Pinto V ${ }^{\mathrm{b}}$, Bandara WRSMc \\ ${ }^{a}$ Teaching Hospital Peradeniya, Sri Lanka \\ 'Teaching Hospital Peradeniya, Sri Lanka \\ 'Department of Anaesthesiology, Faculty of Medicine, University of Peradeniya, Sri Lanka
}

\begin{abstract}
Chronic pancreatitis may cause disabling pain not responding to oral analgesics and/or drainage procedures. Although pancreatectomy is a definitive treatment, it carries a significant morbidity and mortality. Celiac plexus ablation is beneficial, although it is a temporary method for pain relief. While bilateral splanchnicectomy provides a more permanent pain relief, it is a difficult procedure requiring thoracotomy and results in significant morbidity. Thoracoscopy is an attractive alternative to perform splanchnicectomy. The results of a case series on video assisted thoracoscopic sympathectomies performed at the university surgical unit, Peradeniya, Sri Lanka from January 2011 to June 2013 was analyzed to evaluate the surgical technique and to quantify the efficacy of pain relief. Operating time, blood loss, intraoperative complications, conversion to open surgery, pre-operative and post-operative pain assessment using visual analogue scale score (VAS) were recorded. Seven patients who underwent video assisted thoracoscopic splachnicectomy were analyzed. All had an acceptable operating time (6omin), no measurable blood loss, no conversions to open surgery, no intercostal drainage, early mobilization and feeding. All had an average VAS of 8-10 pre-operatively. This reduced to a VAS of 1 or no pain in all, on post-operative day one, at one and six months. The few who experienced mild pain needed occasional use of paracetamol or diclofenac sodium. Non required narcotic analgesics. Bilateral thoracoscopic splanchnicectomy is a safe, effective and more attractive alternative as it carries a minimum morbidity, mortality and provides an excellent relief of chronic agonizing pancreatic pain.
\end{abstract}

KEYWORDS: Thoracoscopy, Splanchnicectomy, Chronic pancreatitis

\section{INTRODUCTION}

Chronic pancreatitis is an inflammatory condition in which the most common symptom being an intermittent or persistent severe pain, which significantly affects the quality of life. Medical management is considered the first line of management followed by other methods. ${ }^{1}$

Management of pain with analgesic drugs often carries the problem of selection, timing and the dose adjustment according to the nature and the severity of the pain. Most commonly used drugs include non-steroidal anti-inflammatory drugs (NSAIDS), Paracetamol, Tramadol, Carbamazepines and opioids. In Sri Lanka, the use of narcotics is being restricted due to the unavailability of the oral preparations for out-patient care.

Corresponding author:

Galketiya $K B$,

Senior Lecturer, Department of Surgery,

Faculty of Medicine, University of Peradeniya,

Peradeniya, Sri Lanka

Fax no: 0094812388371

Telephone: 0094777884008

Email: kbgalketiya@yahoo.com
Furthermore, pain in chronic pancreatitis can be a result of duct obstruction or pseudo cyst formation; it further can be complicated by common bile duct or duodenal stenosis, which needs to be excluded upon the diagnosis. Diagnoses of these conditions warrant surgery. Options for pancreatic duct obstruction are endoscopic retrograde pancreatography and stenting ${ }^{1,2,3}$ or pancreatico-jejunostomy by open or laparoscopic approach and the available options for pseudo cysts are cystogastrostomy or cystojejunostomy. ${ }^{1,4,5}$ It is stated that some patients continue to have disabling pain despite the oral analgesics and/or drainage procedures. These patients can be managed with nerve ablative procedures. Radiological fluoroscopy guided, CT-guided or endoscopic ultrasonography guided6 celiac plexus blocks with alcohol or steroids may achieve pain relief but it is temporary and results were noted to be inconsistent. ${ }^{1,3}$ Also the benefit of this procedure was doubted in patients with previous pancreatic surgery.

Surgical denervation (resection of the greater splanchnic nerve and celiac ganglion) or ablation of the splanchnic nerves or its branches is a well-designed option. ${ }^{1,5}$ This could be done by open surgery which requires bilateral thoracotomy where the morbidity is substantially high. An elegant option would be thoracoscopic ablation of the splanchnic nerves. ${ }^{7-12}$ 
Thoracoscopy provides a clear visualization of the splanchnic nerve branches as it has the added advantage of visualizing a magnified view of the site using the camera. ${ }^{7}$ A precise division of all the branches is thus possible. Comparing to all other methods it carries a lower morbidity and mortality by saving the opening and closing times of thoracotomy and keeping blood loss to a minimum. ${ }^{8,9}$ Currently studies are lacking in this area of expertise. ${ }^{7}$

The aim of this case series is to evaluate the feasibility of the technique and to quantify the efficacy of pain relief achieved by thoracoscopic splanchnicectomy for chronic pancreatic pain.

\section{MATERIALS AND METHODS}

Patients with chronic pancreatitis with persistent pain who were referred to surgical unit since January 2011 to June 2013 were included. Pain was assessed using visual analogue scale.In order to identify duct obstructions or pseudo cyst formation these patients were re-assessed with ultrasound and contrast enhanced computerized tomography. Patients with duct obstruction were directed for endoscopic retrograde pancreatography and sphincterotomy or open pancreatico-jejunostomy. Patients who had pseudo cysts that were symptomatic or larger than $6 \mathrm{~cm}$ were subjected to cystogastrostomy either by open surgery, laparoscopy or endoscopy. Patients who failed to show an improvement of symptoms despite these measures were enlisted for thoracoscopic splanchnicectomy. Prior to this, a pre-operative pain score was recorded using the visual analogue scale.

Bilateral thoracoscopic splanchnicectomy was performed under general anaesthesia with conventional single lumen endotracheal tube with both lung ventilation. Patients were placed in prone position. While ventilating both lungs the ipsilateral lung was collapsed with a capnothorax and the pressure used was noted. Three $5 \mathrm{~mm}$ ports were used. The 30 degree $5 \mathrm{~mm}$ camera port was placed in the $7^{\text {th }}$ intercostal space in the mid axillary line. Two working ports were placed in the $5^{\text {th }}$ and $9^{\text {th }}$ intercostal spaces in the posterior axillary line. The identification details and efficacy of the surgery were noted. The branches from the splanchnic nerves joining the sympathetic chain were identified and ablated with a diathermy hook.

The respiratory and cardiovascular parameters were monitored. The operating time, blood loss, intraoperative complications, conversion to open procedure and post-operative pain score were recorded.

\section{RESULTS}

Seven patients underwent the surgery. There were two females and five males. The age distribution was from sixteen years to sixty years. Table 1 shows the preoperative pain score.

All the thoracoscopic surgeries were performed while ventilating both lungs. The $\mathrm{CO}_{2}$ pressure used

Table 1. Pre-operative pain score

\begin{tabular}{|c|c|c|}
\hline Patient No & $\begin{array}{l}\text { Worst pain score } \\
\text { (visual analogue scale) }\end{array}$ & Current management \\
\hline 1 & $\begin{array}{l}\text { 9: (Frequent intermittent) } \\
3 \text { attacks/day }\end{array}$ & $\begin{array}{l}\text { Paracetamol, Diclofenac sodium, Tramadol, } \\
\text { Carbemazepine, Amitriptyline }\end{array}$ \\
\hline 2 & 10: (Constant) & $\begin{array}{l}\text { Paracetamol, Diclofenac sodium, Tramadol, } \\
\text { Carbemazepine, Amitriptyline, } \\
\text { Pethidine Intramuscular }\end{array}$ \\
\hline 3 & 9: (Constant) & $\begin{array}{l}\text { Paracetamol, Diclofenac sodium, Tramadol, } \\
\text { Carbemazepine, Amitriptyline, } \\
\text { Pethidine intramuscular }\end{array}$ \\
\hline 4 & $\begin{array}{l}\text { 8: (Frequent intermittent) } \\
5 \text { attacks / day }\end{array}$ & $\begin{array}{l}\text { Paracetamol, Diclofenac sodium, Tramadol, } \\
\text { Carbemazepine, Amitriptyline }\end{array}$ \\
\hline 5 & $\begin{array}{l}\text { 10: (Frequent intermittent) } \\
5 \text { attacks / day }\end{array}$ & $\begin{array}{l}\text { Paracetamol, Diclofenac sodium, Tramadol, } \\
\text { Carbemazepine, Amitriptyline, Morphine intravenous } \\
\text { Paracetamol, Diclofenac sodium, Tramadol, }\end{array}$ \\
\hline 6 & 10: (Constant) & Carbemazepine, Amitriptyline, Morphine intravenous \\
\hline 7 & $\begin{array}{l}\text { 9: (Intermittent) } \\
2 \text { attacks / day }\end{array}$ & Paracetamol, Diclofenac sodium, Tramadol \\
\hline
\end{tabular}


was $6-8 \mathrm{mmHg}$. The thoracic sympathetic chain was clearly identified. The branches from the splanchnic nerves joining the sympathetic chain were identified and ablated with the diathermy hook. In few patients these branches were not clearly seen and the sympathetic chain was ablated below T5. Same procedure was performed bilaterally. The respiratory and cardiovascular parameters were stable during the procedure. The peak airway pressure ranged between $16-22 \mathrm{cmH}_{2} \mathrm{O}$. Average operating time was 60 minutes. There was no measurable blood loss. There were no conversions to open surgery. Intercostal drainage was not used and the patients were extubated immediate post-operatively. They were mobilized out of the bed and fed orally on the same day. A re-evaluation of the pain score was done. Table 2 shows post-operative pain score.

Seven patients had a VAS of 8-10 pre-operatively. This reduced to VAS 1 in two patients and no pain in five patients on the first post-operative day. At 1 month four patients had a VAS of 1 to 2 with occasional use of paracetamol or diclofenac sodium. The other two patients did not complain of any pain. After 6 months five patients recorded to have occasional attacks with VAS of 1-2 requiring occasional use of mild analgesics and other two remaining pain free. None of the patients required narcotic analgesics during follow up.

None of the patients had immediate or long term postoperative complications and all were discharged on post-operative day two.

Table 2. Post-operative pain score

\begin{tabular}{|c|c|c|c|c|}
\hline $\begin{array}{l}\text { Patient } \\
\text { no. }\end{array}$ & Post-operative day 1 VAS & $\begin{array}{l}1 \text { month VAS with } \\
\text { analgesic requirement }\end{array}$ & $\begin{array}{l}6 \text { months VAS with } \\
\text { analgesic requirement }\end{array}$ & $\begin{array}{l}\text { Long term } \\
\text { complication }\end{array}$ \\
\hline 1 & $\begin{array}{l}1 \\
\text { (Occasional1attack/ } \\
\text { Day) }\end{array}$ & $\begin{array}{l}1 \\
\text { (Very Occasional } \\
\text { PCM, DS) }\end{array}$ & $\begin{array}{l}0-1 \\
\text { (Very Occasional PCM) }\end{array}$ & Nil \\
\hline 2 & $\begin{array}{l}1 \\
\text { (1 attack/day) }\end{array}$ & $\begin{array}{l}1 \\
(1-2 \text { attacks/Day } \\
\text { Occasional PCM , } \\
\text { DS) }\end{array}$ & $\begin{array}{l}0-1 \\
\text { (Max of } 3 \text { attacks/2day } \\
\text { Occasional PCM) }\end{array}$ & Nil \\
\hline 3 & 0 & $\begin{array}{l}0 \\
\text { (Very rarely PCM) }\end{array}$ & 0 & Nil \\
\hline 4 & 0 & 0 & $\begin{array}{l}0 \\
\text { (Very rarely PCM) }\end{array}$ & Nil \\
\hline 5 & 0 & $\begin{array}{l}2 \\
(1-2 \text { attacks/day } \\
\text { Occasional PCM, } \\
\text { DS) }\end{array}$ & $\begin{array}{l}1 \\
\text { (Very Occasional } \\
\text { attacks/Day } \\
\text { Occasional PCM, DS) }\end{array}$ & Nil \\
\hline 6 & 0 & 0 & $\begin{array}{l}0-1 \\
1 \text { attack/day }\end{array}$ & Nil \\
\hline 7 & 0 & $\begin{array}{l}1 \\
(1-2 \text { attacks/ day } \\
\text { Occasional PCM,DS) }\end{array}$ & $\begin{array}{l}0-1 \\
(1-2 \text { attacks/Day } \\
\text { Occasional PCM) }\end{array}$ & Nil \\
\hline
\end{tabular}

VAS: Visual Analogue Score *Occasional- Only once / day or no use, *Very Occasional - only once in 2-3 days, PCM- Paracetamol, DF- Diclofenac sodium 


\section{DISCUSSION}

Some patients with chronic pancreatitis continue to have disabling pain that significantly affects their quality of life despite medical management and/ or surgical drainage procedures. Although bilateral splanchnicectomy provides permanent pain relief, this option did not gain much popularity over the other methods as it carries the burden of a thoracotomy, which can result in a high morbidity. Thoracoscopy provides an alternate technique with reduced morbidity.

This case series provides evidence that thoracoscopic splanchnicectomy is a safe procedure. All were performed with both lung ventilation, partial lung collapse with capnothorax of $6-8 \mathrm{mmHg}$. This highlights the possibility of the use of this ventilatory technique rather than single lung ventilation using the double lumen tube, which has its own complications. All the patients had stable cardiovascular and respiratory functions. Prone position allowed the collapsed lung to fall away from the field of dissection providing adequate space for dissection. A clear and accurate recognition of the thoracic sympathetic chain and splanchnic nerve branches was possible. The surgery was completed in an acceptable time with no measurable blood loss. There were no conversions to open surgery. All the patients had an uneventful postoperative period requiring no intercostal drainage. All were mobilized and fed orally on the same day and discharged after 48 hours.

There was a dramatic pain relief with five patients having no pain and two with a pain score of 1 on the first post-operative day. After one month three remained pain free and two at six months. Others experienced minor attacks of pain relieved by occasional use of mild analgesics. The results are encouraging but the number of patients studied is small. Varying degrees of success has been reported in other studies. $80 \%$, $68 \%$ and $52 \%$ being pain free at one year is reported in three different studies. ${ }^{9,13,14}$ The study documenting $52 \%$ success at one year records declining values of $38 \%$ and $28 \%$ at two and four years respectively. ${ }^{14}$ Another study documents similar declining success rates of $90 \%$ at 6 months and $49 \%$ at 15 months. A systematic review of 16 studies comprising 484 patients with a median follow-up period of 21 months record a median success rate of $62 \% .{ }^{10}$ The same analysis concludes poor outcome in patients treated with opioids for longer periods and recommends early intervention. 10 This is supported by another study. ${ }^{10}$ The efficacy in relief of pain in pancreatic cancer by thoracoscopic splanchnicectomy is supported by three studies ${ }^{7,12,15}$ and disputed in one. ${ }^{11}$

Overall it appears to be an effective technique with varying degrees of success rates and better used prior to prolong use of opioids. We will have to recruit more patients and follow up for longer period to provide better results.
One study comprising of eight patients has used double lung ventilation as in our study. ${ }^{12}$ One study comprising of 94 patients used lateral position and prone postion in two groups. ${ }^{13}$ The mean operating time was 58.3 minutes in lateral postion and 43.5 in the prone postion. ${ }^{13}$ Prone position is favored in another study. ${ }^{7}$ We used prone position in all patients.

In a systemic review of 202 procedures in 16 reports a conversion rate of $1.3 \%$ is recorded. ${ }^{16}$ Our conversion rate was zero but with only seven patients studied. The mean hospital stay reported in the same review is 2.7 days. We have discharged our patients after 48 hours.

\section{CONCLUSION}

Bilateral thoracoscopic splanchnicectomy provides an excellent relief of chronic agonizing pancreatic pain in this case series. The post-operative morbidity is negligible. Long term results need further evaluation.

\section{Conflict of interest}

None declared.

\section{REFERENCES}

1. Chauhan S, Forsmark CE. Pain management in chronic pancreatitis: A treatment algorithm. Best Pract Res Clin Gastroenterol 2010; 24:323-35.

2. Choi EK, Lehman GA. Update on endoscopic management of main pancreatic duct stones in chronic calcific pancreatitis. Korean J Intern Med 2012; 27:20-9.

3. Avula $\mathrm{H}$, Sherman $\mathrm{S}$. What is the role of endotherapy in chronic pancreatitis? Therap Adv Gastroenterol 2010; 3:367-82.

4. Asri CJ, Jasni H, Ruzaimie MN, Kong CF, Nur Fatin ZA. Combined laparoscopic cholecystectomy and drainage of pancreatic pseudocyst: a case report and review of current management. Med J Malaysia 2013; 68:273-4.

5. Varadarajulu S, Bang JY, Sutton BS, et al. Equal efficacy of endoscopic and surgical cystogastrostomy for pancreatic pseudocyst drainage in a randomized trial. Gastroenterology 2013; 145:583-90.

6. Gress F, Schmitt C, Sherman S, et al. Endoscopic ultrasound-guided celiac plexus block for managing abdominal pain associated with chronic pancreatitis: a prospective single center experience. Am J Gastroenterol 2001; 96:409-16.

7. Cuschieri A, Shimi SM, Crosthwaite G, Joypaul V. Bilateral endoscopic splanchnicectomy through a posterior thoracoscopic approach. J R Coll Surg Edinb 1994; 39:44-7.

8. Tomaszewski S, Szyca R, Jasiński A, Leksowski K. Bilateral posterior thoracoscopic splanchnicectomy in a face-down position in the management of chronic pancreatic pain 
Pol Merkur Lekarski 2007; 22:399-401.

9. Malec-Milewska MB, Tarnowski W, Ciesielski AE, et al. Prospective evaluation of pain control and quality of life in patients with chronic pancreatitis following bilateral thoracoscopic splanchnicectomy. Surg Endosc 2013; 27:3639-45.

10. Issa Y, Ali UA, Bouwense SA, van Santvoort HC, van Goor H. Preoperative opioid use and the outcome of thoracoscopic splanchnicectomy in chronic pancreatitis: a systematic review. Surg Endosc 2014; 28:405-12.

11. Johnson CD, Berry DP, Harris S, et al. An open randomized comparison of clinical effectiveness of protocol-driven opioid analgesia, celiac plexus block or thoracoscopic splanchnicectomy for pain management in patients with pancreatic and other abdominal malignancies. Pancreatology 2009; 9:755-63.

12. Prasad A, Choudhry P, Kaul S, Srivastava G, Ali M. Thoracoscopic splanchnicectomy as a palliative procedure for pain relief in carcinoma pancreas. J Minim Access Surg 2009; 5:37-9.

13. Davis $B R$, Vitale $M$, Lecompte $M$, Vitale $D$, Vitale GC. An objective study of pain relief in chronic pancreatitis from bilateral thoracoscopic splanchnicectomy. Am J Surg 2008; 74:510-4.

14. Buscher HC, Schipper EE, Wilder-Smith $\mathrm{OH}$, Jansen JB, van Goor H. Limited effect of thoracoscopic splanchnicectomy in the treatment of severe chronic pancreatitis pain: a prospective long-term analysis of 75 cases. Surgery 2008; 143:715-22.

15. Katri KM, Ramadan BA, Mohamed FS. Thoracoscopic splanchnicectomy for pain control in irresectable pancreatic cancer. J Laparoendosc Adv Surg Tech A 2008; 18:199-203.

16. Baghdadi S, Abbas MH, Albouz F, Ammori BJ. Systematic review of the role of thoracoscopic splanchnicectomy in palliating the pain of patients with chronic pancreatitis. Surg Endosc 2008; 22:580-8. 
HE INTERNATIONAL MEDICAL JOURNAL MALAYSIA

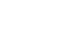

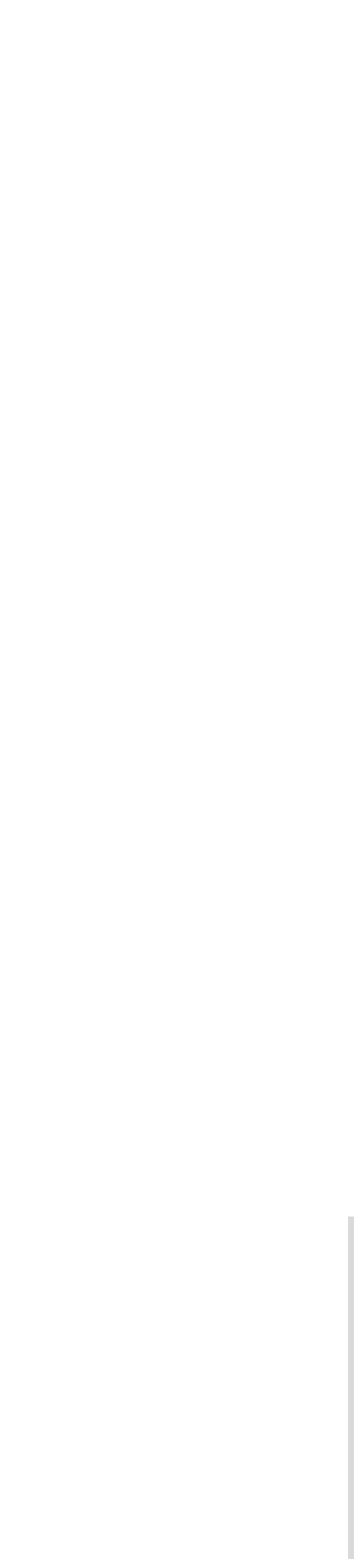

